EASTERN EUROPEAN JOURNAL OF TRANSNATIONAL RELATIONS

2020 Vol. 4 No. 1

DOI: 10.15290/eejtr.2020.04.01.08

James Underwood ${ }^{1}$

University of Northampton, United Kingdom

Hien Quyen Van ${ }^{2}$

University of Northampton, United Kingdom

Ying Zhao ${ }^{3}$

Glocal Education Ltd, China

\title{
Differing Interpretations of Janusz Korczak's Legacy in Schools that take Inspiration from His Work: A Study in Four Schools in the UK and Canada
}

\begin{abstract}
The purpose of this paper is to present how a selection of current school leaders in two countries, other than Poland, the country in which he lived, perceive the legacy of Janusz Korczak. These two countries are the United Kingdom and Canada. Its role is to present these interpretations for debate and discussion among other school leaders and practitioners, who claim inspiration from him worldwide. We have not suggested that there is a correct or incorrect way to interpret Korczak, rather we are simply interested in how current practitioners perceive his work. The first part of this article is a brief summary of key aspects from the life and works of Janusz Korczak that have entered educational conversation within the United Kingdom and the wider Anglophone world. This has often been through writings by and for teachers or books written for schools, rather than academic texts or even Korczak's original works. Key aspects of his life story presented here are: those years leading the orphanage 'Dom Sierot', and most especially the final months of his life in the Warsaw ghetto, and the last recorded events of his life, including his refusal to go to Theresienstadt and his
\end{abstract}

1 Principal Lecturer in Education - University of Northampton, MA Education and PhD Education from the University of Cambridge. ORCID: 0000-0001-9351-2408. E-mail: james.underwood@ northampton.ac.uk.

2 MA Education graduate - University of Northampton. ORCID: 0000-0001-7232-984X. E-mail: vanhienquyen@gmail.com.

3 General Manager, Glocal Education Ltd - China, MA in Management from the University of Durham. ORCID: 0000-0002-0585-5775. E-mail: tyouei79@ hotmail.com. 
ultimate death in Treblinka. We also present in this section, because of an expectation that schools may have engaged with these, his views on how societal structures being designed by adults disadvantage children; and his valuing of children's voices, as well as his views on the problematic nature of authority. This paper is a discussion of four linked case studies. Participants for this study were four school leaders, two from the UK and two from Canada. The schools they lead are schools that in public facing aspects of their schools, such as school webpages or public vision statements, refer explicitly to the influence of Janusz Korczak. The method of data collection used within this study was unstructured interviews with school leaders. Through this process we discovered that there are commonalities in how his legacy has been perceived. These included, for all, intertwining his life and work and in doing so presenting him as a role model to children and teachers. Other aspects of his influence focused on student voice, the breaking down of hierarchy and the enabling of creativity.

Keywords: Janusz Korczak, school leadership, power distance, student voice

\section{Introduction}

This article is the first article published as part of a research project into the legacy of Janusz Korczak, the Polish writer of novels for children and of books and articles about teaching, parenting and childhood. For this study we approached four school leaders all leading different schools which openly claim to base their vision and their practice, at least partially, on the works of Janusz Korczak. Via unstructured interview we explored what his legacy meant to them. We did this without judgment. Our aim was not to catch schools out or to identify best practice but simply to attain an overview of the different ways in which his legacy is interpreted today. In this article therefore we first present a conceptual framework regarding the life and work of Janusz Korczak, this is followed by a short description of our methods and finally we present our findings. This project was designed around a single research question as follows: How do the leaders of different schools, who claim to take inspiration from the Polish writer Janusz Korczak, interpret this?

\section{Conceptual Framework}

This section of this article presents a brief summary of key concepts from the life and works of Janusz Korczak that have entered educational conversation within the United Kingdom and the wider Anglophone world, often through writings by and for teachers, or books written for schools, rather than academic texts or even Korczak's original works. This section therefore is not an exploration into the intricacies of his ideas based on academic texts but rather is an elucidation of key aspects that may have inspired current practitioners due to their accessibility in texts practitioners 
may read. Its purpose is to contextualise the findings from the interviews with school leaders.

Excellent texts on the works of Janusz Korczak approach his writings in depth (Silverman, 2017). Indeed research and writing regarding Janusz Korczak is a live and constantly developing field, especially in Israel and Poland but elsewhere, too. Beyond this, of course, Korczak's own works are still engrossing and thought provoking reading for anyone interested or involved in education or working with children. A compendium of selected works easily accessible in English has been recently collated by Medvedeva-Nathoo and Czernow (2018).

However, in constructing this framework and writing this article we recognised that it may well be that even those practitioners who take inspiration from Korczak do not read Korczak's original writings frequently or in depth and perhaps rarely read academic texts, addressing his thinking, at all. Indeed for many children and teachers a popular play written for school drama courses has been an introduction to Korczak (Grieg, 2004). More recently novels in English for adults and for children such as those written by Belfer (2018), Gifford (2018) and Marrin (2018) have been an introduction for many, too. However, despite the way Korczak's legacy has been filtered before reaching them, it is still in the voices and actions of practitioners: teachers, teaching assistants, and school leaders that any writer on education, including Korczak, lives on.

This article is also pertinent to the present day because interest in Korczak has grown in schools in the United Kingdom in recent years. The factors that have led to this have been linked primarily to Polish immigration which has led to an increase in Polish students, in Polish teaching assistants and to a lesser extent in teachers of Polish origin (Smith, 2020). This should not be over-stressed and is less so in Canada where recent Polish migration has been less marked than in the United Kingdom. Korczak is still a marginal figure on most teacher training courses in the United Kingdom and in other Anglophone countries. However, through dialogue within schools, between practitioners familiar with his significance in Poland, his is now a name that is becoming part of the conversation in schools in the United Kingdom. It is increasingly familiar to many teachers. Indeed trainee teachers returning to university classes having picked up his name within school practice have led to his inclusion on some courses in United Kingdom universities, in itself this has been an interesting process of schools informing the university curriculum (Smith, 2020).

The first aspect of Janusz Korczak's legacy that we expected schools to explicitly refer to, based on an initial analysis of writings about Korczak, in sources that teachers frequently read and use in their teaching (Yad Vashem, 2020; Holocaust Memorial Day Trust, 2020) was his life rather than his writings. Indeed on visiting the two schools in the UK, whose leaders participated in these interviews, early in the research process, this clearly was the case. In both these schools there were posters 
on walls and brief two or three sentence summaries of key life events. There were also short quotes from Korczak's writings.

Some aspects of his life that we expected may be referred to included his Jewish heritage, his life as a writer of journalism and of children's stories, and his training as a paediatrician. However, we expected that as regards his life story more emphasis would be placed on his years leading the orphanage 'Dom Sierot', the community that he built there and most especially the final months of his life in the Warsaw ghetto and the last recorded events including his refusal to go to Theresienstadt and his ultimate death in Treblinka.

The second aspect we expected to be referred to was his writings on pedagogy, especially those contained in compendiums in English, easily available in Canada and the United Kingdom (Medvedeva-Nathoo \& Czernow, 2018). These writings are wide and extensive and some aspects contain passionate arguments that in the schools we were interviewing within are now resolved by history. The most obvious example of these is that Korczak was a passionate opponent of corporal punishment. Which at the time was universally practiced across Europe but which is illegal in the jurisdictions in which all these schools are based. However, other aspects of his work referred to in the texts teachers and school leaders may access are more contentious to this day. These include a belief that childhood is a distinct stage of life that should be valued as having its own intrinsic worth, and that childhood therefore is more than simply a transition to adulthood. We also expected that schools may have engaged with debates regarding whether societal structures being designed by adults disadvantage children.

Furthermore, Korczak wrote extensively and in various contexts of the power imbalance between adults and children. He was concerned that power that came through physical strength or that was imposed upon others damaged children and damaged society. He also believed in the capacity of children to interpret their world in a way that was as, or more, valid than the adult interpretations that might be imposed upon them. He highly valued the voice and understandings of children. He had trust in the capacity of children to function as independent decision makers and had faith in the decisions of children. This was expounded on in his discussions on aspects of childhood such as mealtimes and bedtimes, some of which continue to be counter-norm and provocative even to this day. These again were themes we had found emphasised in accessible writings on Korczak as found in mainstream media related to education in the United Kingdom (Johnson, 2020; Muller, 2020).

Lastly, we expected these school leaders may link Korczak's writing and the ways it had influenced their thinking to the ideas and influences of other writers. We expected that this may include linking Korczak's ideas specifically to those of other seminal, progressive writers on education such as Paulo Freire, John Dewey and Maria Montessori. However, we also expected interweaving with contemporary writers especially where schools had engaged in teacher leadership projects. 
These could include Alma Harris (2013); David Frost (2015) and others linked to David Frost's writing and work philosophically and professionally: Joshevska and Kirandziska (2017); or Underwood and Kowalczuk-Walędziak (2019).

As stated earlier, this conceptual framework is very brief and not intended to be an exploration into his writings and ideas. It is rather a short presentation of a framework of those concepts from his life and works that have entered the educational conversation in the UK often from journalism or textbooks rather than academic writings and that we expected the teachers who were interviewed to refer to.

\section{Study Design}

In this section we present a brief summary of the methods used when undertaking this research project. This begins with a brief description of the participants, followed by the processes of data collection and data analysis, and lastly there is a short paragraph in which ethical considerations are discussed.

The participants for this study were four school leaders in schools that in public facing aspects of their work referred to Janusz Korczak. In all cases he was referred to explicitly on front facing webpages and within published school vision documents. Korczak is widely studied on teacher training courses and is part of the public discourse in Poland. However, one contribution of this paper is to gain an understanding of his relevance to school leaders outside Poland, specifically in the Anglophone world. Therefore, the case study schools for this project were two schools in England and two schools in Canada. In each country one of the schools was a state secondary school and one was a state primary school, although one was affiliated to the Church of England.

The method used was unstructured interview. The participants were interviewed in private and the interviews in all cases lasted approximately 40 minutes. At the start of the interview the participants were asked the same question after which a natural, professional conversation was allowed to simply evolve via prompts and further questions. The initial question asked was identical to the research question at the top of this article. These interviews were recorded and transcribed, prior to a deeper textual analysis. Participants were told the topic of the interview in advance and in some cases even brought illustrative materials in order to be ready to discuss further.

British Education Research Association guidelines were followed throughout (BERA, 2018). This is a low-risk study. The topic under investigation was one that participants were content to discuss openly, indeed was an openly addressed aspect of their school's identity. All the participants were highly qualified adults in positions of professional authority. They understood concepts of informed consent and anonymity easily and had the professional confidence to withdraw if they wished. 


\section{Findings}

In this section we present quotations from the interviews. These are accompanied by our commentary and interpretation. The sub-headings are based on the four strongest and most consistently referred to themes that emerged from the interviews.

\section{Korczak's Life Story as Legacy}

As expected all the school leaders referred to the story of the life of Janusz Korczak as an important reference point for their school. These two quotations below illustrate two subtly different ways in which these schools interpreted the relevance of his life to children and teachers today.

I think his life is a legacy. I think a lot of schools in the country would take inspiration from Korczak but I don't know, I might not be typical. However, to me 'how to love a child' for example didn't give me strategies. You know in some ways, many ways, it is positioned in place and time. So equating the resources, the space, the culture of a modern school to a school in Korczak's era is not really possible. However, from his life story and the commitment of his last days you can understand what a teacher is, what a school is for. You can get that understanding of the moral purpose of what we do. That is what we get and that is how we present Korczak to the students. So in our commitment to our school and our students he informs practice but perhaps not so much in the detail of what we do.

As this quotation illustrates, firstly this School Principal has identified a challenge in interpreting the teaching practices espoused in some of Korczak's most well-known works when working in a modern classroom situated in contemporary society. However, using language familiar in more recent debates from teacher leadership perspectives, (Frost, 2015) she then goes on to discuss the message of moral purpose that is gained by teachers through the stories of Korczak's life. Practice and purpose have been previously identified as distinct forms of knowledge, which together constitute the four types of knowledge that teachers possess, the others being strategy and affirmation (Underwood \& Kowalczuk-Walędziak, 2019). Moral purpose particularly has been defined as: why teachers teach and why they teach how they do (Frost, 2015). It has also been defined as: those beliefs and values that lead to teachers engaging in extending their professionalism (Joshevska \& Kirandziska, 2017). The connection between Korczak's life story and the moral purpose of teachers, identified by the school leaders, is the way that Korczak asserted, by his actions, the central importance of teaching to a society and the complete commitment to teaching and the care of children that he showed. 
I would say his life story is his greatest legacy to us as a school. It is a story we tell to every child every year as part of our Holocaust Memorial Day remembrance. It is a very powerful story to us. A story about the deep moral purpose of what it means to be a teacher, what it means to care. It is such a powerful story of peaceful heroism .... However, he is complicated if seeking practice. A Child's Right to Respect and How to Love a Child are as much for parents as for students. Individual paragraphs from these books are fantastic for provoking thoughts and debates. However, it functions more for prompts to provoke ideas than as a guide.

For this leader, as for the school leader quoted above, Korczak provides affirmation, purpose and inspiration but not precise teaching strategies. However, this is not problematic for her. The training she provides for her staff, in which she uses quotations from Korczak, is in the form of discussions that introduce and open up debates. Korczak's wide-ranging writings for her are an entry point for enabling the teachers' own creativity. From both these quotations it is clear that Korczak's life story provides affirmation as fellow professionals and a sense of moral purpose for teachers. It serves as an inspiring story for teachers which helps them to continue in and to be proud of their job. Furthermore, his life story indirectly inspires students through teachers, with teachers passing his legacy to different generations of students in their schools.

\section{Korczak and Student Voice}

Within both the countries referenced in this study there is an emphasis on the importance of student voice. This comes from government advice, and teacher training institutes. Worldwide, the intellectual tradition regarding student voice is complex with many different writers having a role in shaping and defining this. Despite this complexity the leaders of these specific schools linked their understanding and interpretation of student voice to their understanding of Korczak. Although they also referred to other writers who had inspired their understanding of student voice. These two quotations below illustrate this:

To me Korczak has had a very direct impact on practice. So I can list concrete things. We start the school day later than other schools because actually to me an early start is enforcing adult biology on children. You know teenagers simply have a different biological sleep pattern. It is not that they are lazy, the melatonin is just released later. Now that comes right back to Korczak, I can find the exact quote where he discusses it, in English 'the tyranny of bedtime'. 
This quotation links the development of a specific school policy directly to the writings of Korczak. Interestingly in making this policy, this school leader has referred specifically to a passage from Korczak's seminal work 'How to Love a Child'. In the interview she also referred to how she found it useful to reference his writing when engaging with staff as this could be persuasive when bringing in change. This is because she was aware that her staff had a deep respect for his work.

Yes, we take practice from Korczak - the children's council is one and in our school you know this council has more real influence than others. They don't just plan an end of term party or something like this they have influence on bigger strategic things. Not a final decision but we will bring to the council plans for the new drama studio or plans for what options will be available in year 9 or what have you. I suppose the only way we don't take practice is that in many ways the classroom of today has changed. So it is structures we take not actual, the detail of classroom tasks perhaps.

This principal again describes how they have been directly influenced by Korczak in the ways that they have structured the processes by which they access student voice. This has specifically involved the creation of the student council. However, this structure can also frequently be found in schools that do not claim to have been directly influenced by the ideas of Korczak. This is one complexity with identifying the legacy of a seminal writer. Their writings intersect with the ideas of others and with broader cultural and societal changes. Still it remains significant that in both these schools the school leadership has interpreted decisions that they have made as having been influenced by Korczak.

\section{Korczak and Power Distance}

Power distance is not a phrase that Korczak himself used, and it therefore has to be used with caution in relation to him. However, we have used the phrase, power distance, because these current school leaders, when interviewed, did use it. This illustrates the complexity of identifying an intellectual legacy. Korczackian concepts were repeatedly interwoven with more recent concepts and expressions by the participants during the interviews. All the interviewees clearly expressed a link between Korczak's ideas and contemporary concepts of breaking down power-distance in order to create flatter, more discursive leadership structures. These two quotations illustrate how the school leaders used this term in relation to Korczack's ideas.

I think Korczak shapes a lot of how I think as a leader. I think this goes beyond teacher student relationships and what I am talking about is relationships within the whole school. So I wanted to break down power distance in this. Because I think it is a right thing to do but also because 
I think it means more creative teachers, more innovative teachers. Teachers who take control of things themselves.

In this quotation this school leader describes how Korczak's views on leadership have shaped the relationship that she has with children and with staff. Hers is a view of leadership that fits with conceptualisations of distributing leadership put forward by recent writers such as Alma Harris (2013). Korczak emphasised how less hierarchical models of leadership based on listening and acknowledging the expertise of others, including the expertise of children, have ethical value. This leader builds on this to describe how moving away from a more directive approach to leadership, and instead recognising the expertise of colleagues has enabled creativity among her teachers and has led to school improvement.

To me Korczak was ahead of his time. He was interested in breaking down power distance. He was interested in breaking hierarchies. This kind of fits with ideas that have been important to me recently. This has connections to teacher leadership, non-positionality, all these important ideas about empowerment by breaking hierarchy.

This school leader went on to explain how his interest in Korczak's ideas had led to a broader interest in alternative leadership structures and especially into the concept of non-positionality. In his interview he linked Korczak's emphasis on leaders who listen, acknowledge others, and lead via dialogue and persuasion to more recent writings about 'teacher leadership'. This school leader's conceptualisation of teacher leadership is clearly strongly based on the ideas of David Frost (2015) and also on the writings of practitioner academics such as Majda Joshevska (Joshevska \& Kirandziska, 2017). However, this school leader linked these more recent writers to Korczak's intellectual legacy. This is noticeably not a connection that these writers themselves make. Thoughtful teachers and leaders when presented with ideas from a range of seminal and contemporary writers will start to make their own idiosyncratic and personalised links. This is an important form of knowledge creation that exists within the reflective dialogue of teachers both as an internal conversation and in conversation with others. Teachers use the ideas of a range of writers in order to create their own personalised vision and philosophy, which is shaped by personal experience. The direct legacy of one writer therefore becomes hard to untangle from others. The writers become useful tools in which to logically build personalised interpretations.

\section{Korczak and Teaching Practice}

All the interviewees referred knowledgeably and with passion to the importance that the ideas of Janusz Korczak have had on shaping their vision and practice as school leaders. However, all of them also admitted that it was challenging to identify 
his influence on the specifics of classroom practice. This may be, as the interviewees stated, because he is not a writer on education in a conventional sense. His goal was to provide, through a narrative of his experiences, an over-arching vision of childhood beyond classrooms. It may also be, which these school leaders did not identify, that as school leaders they are less engaged in classroom teaching. It is possible that future interviews with teachers, as this project develops, may elicit a different interpretation. However, these quotations below illustrate that these school leaders still saw Korczak's legacy on classroom practice as present even if somewhat difficult to pin down to specifics.

Well I think Korczak runs through our teaching practice. But I mean sometimes it can be hard to distinguish because these progressive writers shaped education and they overlap. So is it Dewey? Is it Korczak? Is it Montessori? It can be hard to know where any particular item of practice comes from. However, I think Korczak runs through practice. I would identify things like asking children's views, taking their interpretations seriously, not criticising the quiet child but finding a way in which to involve them. Even 'pair-share' is a Korczakian concept. 'A guide on the side not a sage on the stage' is a Korczackian statement, even if not words Korczak wrote himself.

As this quotation illustrates, this School Principal has identified the complex process, whereby a widely read professional, will synthesise a range of writers when building their vision for teaching and running schools. A good illustration of this is the sentence in which she ascribes the practice idea of 'pair-share' to a Korczackian approach to education even though it is more usually attributed to more recent writers on practice. 'A guide on the side not a sage on the stage' is a phrase of uncertain origin, but that is often taught as a simple reminder to new teachers in the United Kingdom to encourage them to design lessons that are not simply focused on the teacher as dispenser of knowledge. Again this Principal links this to her understanding of Korczak, while being clearly aware that these are not words attributable directly to him.

One of my worries is that we have elevated practice at the expense of denigrating pedagogy. This is seen in entirely school based training but, and I know this is not a popular view it is also at the expense of no longer expecting lecturers to be writers. If universities are to offer something different from school-based training it needs to be linking students to a long history of pedagogical thinking. There are too many young teachers coming into the profession thinking that they invented child-centred pedagogy. They make great statements on teaching but without knowing that Korczak, Freire and others got there first. 
This final quotation addresses a wide-ranging critique of contemporary education policies in the UK. These are current and contentious debates. She refers to a movement in England away from university based teacher training to school based. She also refers to debates regarding whether university lecturers should be writers too or whether substantial professional experience is sufficient if one is to train others professionally. She positions herself clearly regarding these debates and consistently within the rest of her interview values practitioners having a deep understanding of writers on education both seminal and recent. She identifies two writers and links them clearly in her mind, this is even though this is not a connection that Freire, the latter of these two writers, writing in a Brazilian context in the 1970s, explicitly made.

\section{Conclusion}

The purpose of this paper is to present how a selection of current practitioners in two countries, other than Poland the country in which he lived, perceive the legacy of Janusz Korczak. We have presented these interpretations for debate and discussion among other practitioners who claim inspiration from him worldwide. We have not suggested that there is a correct or incorrect way to interpret Korczak. However, as is explored throughout the article there are commonalities in how his legacy has been perceived. These include the intertwining of his life and work, portraying him, through his actions as well as his words, as a role model for children and teachers. Another is positioning him as a writer within a canon of progressive pedagogues who he is linked to conceptually including: John Dewey, Paulo Freire, and Maria Montessori. Differences emerged regarding the influence of Korczak on practice. To some, structures such as student councils were examples of a direct legacy of practice. To others, it was values and broader brush ideas that he has left to teachers, who then must interpret these in their own creative ways. A next stage for us will be to provide further articles for discussion and debate exploring his legacy. One we already have in process is a paper into his legacy on classroom teachers who acknowledge his influence. Another is to explore the perception of children in these schools. Quantitative research into the awareness of Korczak among practitioners and school leaders would also help us ascertain how far his ideas are now moving towards the knowledge mainstream in the United Kingdom, Canada and elsewhere. These deeper understandings should be of interest to practitioners and to facilitators of teacher-training programmes alike. 


\section{EASTERN EUROPEAN JOURNAL OF TRANSNATIONAL RELATIONS}

\section{REFERENCES}

Belfer, I. (2018). Janusz Korczak: The Man Who Knew How to Love Children: The Educational Philosophy \& Life of the Great Teacher Told By his Admiring Student - A Child Holocaust Survivor. Yanuka, Poland.

Frost, D. (2015, September). The role of teacher leadership in the transition to democratic society. Paper presented at the European Conference on Education Research (ECER) 2015. Budapest, Hungary.

Gifford, E. (2018). The Good Doctor of Warsaw. London: Corvus.

Grieg, A (2004). Dr Korczak's Example: a play. Edinburgh: Capercaillie Books Limited.

Harris, A. (2013). Distributed leadership matters: perspectives, practicalities, and potential paperback. California, USA: Corwin Press.

Holocaust Memorial Day Trust. (2020). Resources about Janusz Korczak. Retrieved from: https:// www.hmd.org.uk/resource/janusz-korczak/, UK: HMD.

Johnson, D. (2020, May). A history teachers journey: why we should all know more about Korczak's pedagogy as well as his life. Paper Presented at the British Council Teachers' Partnership Conference, London.

Joshevska, M., \& Kirandziska, S. (2017). The rise and rise of teacher leadership in Macedonia. In D. Frost (Ed.), Empowering teachers as agents of change: a non-positional approach to teacher leadership (pp. 79-84). Cambridge, UK: The Cambridge Network. Retrieved from https://www.hertscam.org.uk/uploads/2/5/9/7/25979128/blue_e-book.pdf.

Marrin, A. (2018). A Light in the Darkness: Janusz, Korczak, His Orphans, and the Holocaust. New York. NY : Knopf Books for Young Readers.

Medvedeva-Nathoo, O. \& Czernow, A. M. (2018). How to love a child and other selected works by Janusz Korczak. London, Chicago, IL: Vallentine Mitchell.

Muller, B. (2020). Children under the Nazis. Resources for Teachers. Newcastle: University of Newcastle.

Silverman, M. (2017). A Pedagogy of Humanist Moral Education: The Educational Thought of Janusz Korczak (1st ed.). New York, NY: Palgrave MacMillan.

Smith, J. (2020, January). Learning from Polish colleagues. Paper presented at the ASCL Regional Conference. January. Cambridge, UK.

The British Education Research Association (BERA). (2018). British Education Research Association revised ethical guidelines for educational research. UK: BERA.

Underwood, J., \& Kowalczuk-Walędziak, M. (2019). Professional communities among teachers: a summary of a conceptual framework. Polish Journal of Education Studies, 71(1).

Yad Vashem. (2020). Resources for Middle School Children, Janusz, Korczak. Retrieved from: https:// www.yadvashem.org/education/educational-materials/learning-environment/janusz-korczak. html, Jerusalem: Yad Vashem. 